\title{
PEMERIKSAAN KESEHATAN DAN KONSULTASI OBAT PADA PERHIMPUNAN WARAKAWURI SANTA MONIKA SAMARINDA
}

\author{
${ }^{1}$ Josepha Benciang, ${ }^{2}$ Martina Norsanah dan ${ }^{3}$ Liniati Geografi \\ 1,2 Program Studi DIII Keperawatan Stikes Dirgahayu Samarinda \\ ${ }^{3}$ Program Studi S1 Farmasi Stikes Dirgahayu Samarinda \\ Jalan Pasundan No.21 Telp (0541) 748335, Fax. (0541)748335 \\ Alamat surel (e-mail) : benciangyosepha@gmail.com
}

\begin{abstract}
ABSTRAK
Perhimpunan Warakawuri Katolik Santa Monika merupakan suatu wadah Ibu-ibu janda / wanita Katolik yang tidak menikah, dengan usia rata-rata 60 tahun. Tujuan kegiatan ini adalah: mengetahui tekanan darah, berat badan, kadar kolesterol, asam urat, glukosa darah peserta, promosi kesehatan sesuai dengan kondisi peserta, baik secara langsung maupun dengan bantuan brosur dan membuka konsultasi terkait kepatuhan peserta dalam menjalankan terapi obat. Penyuluhan dilakukan kepada peserta yang mengalami hiperkolesterolemia (kadar kolesterol $\geq 200 \mathrm{mg} / \mathrm{dL}$ ) dan hipertensi (tekanan darah $>140 \mathrm{~mm}$ $\mathrm{Hg}$ ). Hasil rata-rata dari empat kali pemeriksaan kesehatan menunjukkan bahwa 18 orang $(78 \%)$ mengalami hiperkolesterolemia, 12 orang (52\%) mengalami hiperurisemia (kadar asam urat $\geq 6 \mathrm{mg} / \mathrm{dL}$ ), 10 orang (42\%) mengalami hipertensi, dan 2 orang (9\%) memiliki kadar glukosa darah $\geq 200 \mathrm{mg} \%$. Mengingat besarnya manfaat kegiatan ini, maka selanjutnya perlu diadakan penyuluhan kesehatan secara berkesinambungan agar memberikan manfaat yang lebih optimal terhadap peningkatan kualitas hidup anggota Perhimpunan Warakawuri St. Monika Samarinda.
\end{abstract}

Kata Kunci: Hiperkolesterolemia, Hiperurisemia, Hipertensi, Konsultasi Obat, Pemeriksaan kesehatan lansia

\begin{abstract}
The Santa Monika Catholic Warakawuri Association is a place for unmarried Catholic women/ widows, with an average age of 60 years. The purpose of this activity is: knowing the blood pressure, body weight, cholesterol levels, uric acid, blood glucose participants, health promotions that are tailored to the conditions of the participants, both directly and with the help of brochures and opening consultations related to participant compliance in carrying out drug therapy. Counseling was carried out for participants had hypercholesterolemia (cholesterol level $\geq 200 \mathrm{mg} / \mathrm{dL}$ ) and hypertension (blood pressure $>140 \mathrm{~mm} \mathrm{Hg})$. The average results showed that 18 people $(78 \%)$ had hypercholesterolemia, 12 people $(52 \%)$ had hyperuricemia (uric acid levels $\geq 6 \mathrm{mg} / \mathrm{dL}), 10$ people $(42 \%)$ had hypertension, and 2 people ( $9 \%$ ) had blood glucose levels $\geq 200 \mathrm{mg} \%$. Considering the magnitude of the benefits of this activity, then it is necessary to hold health education on an ongoing basis in order to provide more optimal benefits to improving the quality of life of members of the Santa Monika Catholic Warakawuri Association Samarinda.
\end{abstract}

Keywords: Drug Consultation, Hypercholesterolemia, Hyperuricemia, Hypertension, Elderly health examination 


\section{PENDAHULUAN}

Perhimpunan Warakawuri Katolik Santa Monika adalah suatu wadah Ibu-ibu janda/Warakawuri Katolik yang bersifat sosial dengan dasar pelayanan dalam cinta kasih Kristiani dan tidak bernaung pada partai manapun. Anggota himpunan ini terdiri dari beberapa tipe, yaitu Single parent family, the single adult living alone, extended Family dengan usia ratarata 60 tahun.

Seiring perjalanan dan pertambahan usia, proses penuaan pun terus berlangsung dan menimbulkan berbagai macam perubahan. Tubuh akan mengalami perubahan pada struktur dan fisiologis dari berbagai sel, jaringan ataupun organ dan sistem yang menyebabkan involusi dan degradasi sehingga tubuh menjadi rentan terhadap macam penyakit terutama penyakit degeneratif.

Menurut hasil pemeriksaan yang dilakukan pada tahun 2017, dari 59 anggota 25 orang diantaranya memiliki tekanan darah sistolik diatas $150 \mathrm{mmHg}$, 20 orang dengan kadar kolesterol diatas $200 \mathrm{mg} / \mathrm{dL}$, dan asam urat diatas $6 \mathrm{mg} / \mathrm{dL}$. Beberapa anggota himpunan ada yang mengkonsumsi obat kolesterol, tapi dari hasil wawancara, seringkali konsumsi obat dihentikan sendiri oleh yang bersangkutan karena merasa jenuh saat meminum obat atau tidak menyadari tingginya kadar kolesterol yang dialami. Hal ini membutuhkan perhatian jika ditinjau dari sisi kesehatan. Perlu dilakukan usaha promotif, preventif, kuratif dan rehabilitatif agar para lansia dapat menikmati hari tua yang bahagia dan berguna.

\section{METODE}

\section{Alat dan Bahan}

Alat yang digunakan pada pemeriksaan kesehatan di Perhimpunan Warakawuri Santa Monika Samarinda meliputi: timbangan badan, tensimeter, stetoskop, alat tes darah (Autocheck), lancet device, daftar absensi, alat tulis, brosur penyuluhan dan kertas kerja yang memuat data berat badan, tekanan darah, kadar kolesterol, kadar asam urat, dan kadar glukosa darah dari peserta. Bahan yang digunakan meliputi: jarum lancet steril, alcohol swab, strip kolesterol, asam urat dan glukosa Autocheck.

\section{Metode Pelaksanaan}

Pada kegiatan PKM di

Perhimpunan Warakawuri Santa Monika Samarinda ini, terdapat dua jenis kegiatan yaitu pemeriksaan kesehatan dan penyuluhan. Pemeriksaan kesehatan yang dilakukan meliputi penimbangan berat badan, pengukuran tekanan darah, pemeriksaan kolesterol, asam urat dan gula darah. Setelah pemeriksaan kesehatan dilakukan, hasil pemeriksaan dicatat, disampaikan serta didokumentasikan.

Penyuluhan dilakukan terutama kepada peserta yang menurut hasil pemeriksaan, memiliki kadar kolesterol total di atas nilai normal $(\geq 200 \mathrm{mg} / \mathrm{dL})$ dan tekanan darah diatas normal $(>140$ $\mathrm{mm} \mathrm{Hg}$ ). Penyuluhan berupa penggunaan obat dan pola makan/ nutrisi yang tepat dilakukan dengan menggunakan media brosur. Penyuluhan penggunaan obat dilakukan secara bertahap mulai dari pengenalan penyakit, tanda \& gejala, perubahan gaya hidup yang dapat mendukung perbaikan kondisi, terapi obat kolesterol dan hipertensi hingga cara pengelolaan obat yang benar (DAGUSIBU). Penyuluhan tentang pola makan/ nutrisi bagi penderita kolesterol dan hipertensi dimulai dengan penyebab kolesterol tinggi, bahaya kolesterol tinggi, hal yang harus dilakukan pada saat kolesterol tinggi, makanan yang tidak boleh dikomsumsi, makanan yang perlu dibatasi serta makanan yang dianjurkan. Peserta juga dipersilahkan berkonsultasi tentang terapi obat yang sudah dijalani dan diet yang tidak dipahami. 
HASIL DAN PEMBAHASAN

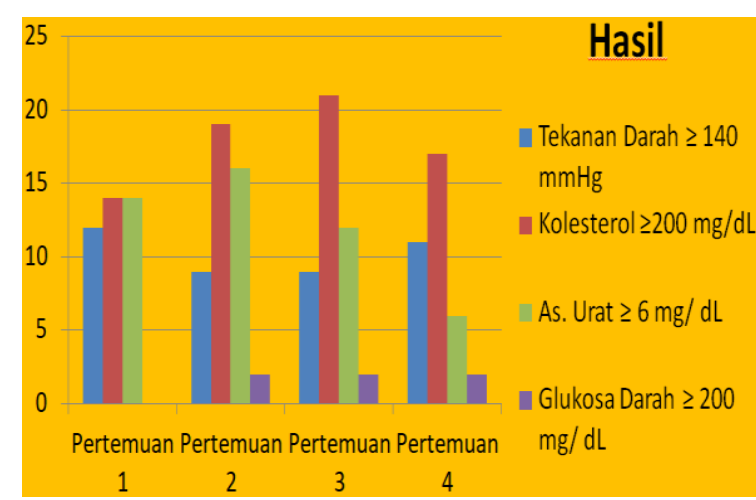

Gambar 1. Data jumlah peserta dengan hasil nilai diatas normal pada setiap pemeriksaan kesehatan

Pelaksanaaan pengabdian masyarakat di Perhimpunan Warakawuri Santa Monika Samarinda ini dilakukan sebanyak 6 kali yang terdiri dari 4 kali pemeriksaan kesehatan yang meliputi penimbangan berat badan, pengukuran tekanan darah, pemeriksaan kolesterol, asam urat dan gula darah serta 2 kali penyuluhan. Hasil rata-rata dari 4 kali pemeriksaan kesehatan terhadap anggota yang rutin hadir menunjukkan bahwa 18 orang $\quad(78 \%) \quad$ mengalami hiperkolesterolemia, 12 orang (52\%) mengalami hiperurisemia (kadar asam urat $\leq 6 \mathrm{mg} / \mathrm{dL}), 10$ orang $(42 \%)$ mengalami hipertensi, dan 2 orang $(9 \%)$ memiliki kadar glukosa darah $\leq 200 \mathrm{mg} \%$. Dari hasil wawancara selama penyuluhan juga diketahui bahwa peserta memiliki dua kecenderungan untuk menghentikan penggunaan obat, yaitu karena merasa jenuh dengan rutinitas tersebut atau tidak menyadari tingginya kadar kolesterol/asam urat/ tekanan darah/ glukosa darah yang dialami.

Menopause merupakan salah satu faktor yang tak dapat dimodifikasi (nonmodifiable) penyebab meningkatnya kadar kolesterol pada seorang wanita. Pada saat usia semakin bertambah, wanita akan mengalami penurunan kadar hormon estrogen yang membuat kemampuan tubuh dalam menyeimbangkan kadar kolesterol menjadi terganggu. Peranan estrogen sebagai antioksidan adalah mencegah proses oksidasi Low-density lipoprotein (LDL) sehingga kemampuan LDL untuk menembus plak akan berkurang. Peranan estrogen yang lain adalah sebagai pelebar pembuluh darah jantung sehingga aliran darah menjadi lancar dan jantung memperoleh suplai oksigen secara cukup. Hal ini juga dapat meningkatkan resiko penyakit jantung sehingga dibutuhkan penyuluhan untuk mengingatkan kepada peserta mengenai pentingnya mengontrol kadar kolesterol baik secara terapi obat maupun melalui pengaturan pola makan.

Penurunan hormon estrogen pada wanita menopause juga berpengaruh pada munculnya kejadian hiperurisemia. Terjadi penurunan ekskresi asam urat di dalam darah melalui ginjal dan mengakibatkan menumpuknya asam urat di dalam darah. Tekanan darah pada usia lanjut (lansia) akan cenderung tinggi sehingga lansia lebih besar berisiko terkena hipertensi (tekanan darah tinggi). Bertambahnya umur mengakibatkan tekanan darah meningkat, karena dinding arteri pada lansia akan mengalami penebalan yang mengakibatkan penumpukan zat kolagen pada lapisan otot, sehingga pembuluh darah akan berangsur-angsur menyempit dan menjadi kaku.

\section{KESIMPULAN DAN SARAN}

Penurunan fungsi fisiologis tubuh pada usia lanjut merupakan salah satu faktor yang menyebabkan tubuh menjadi rentan terhadap penyakit diantaranya hiperkolesterolemia, hiperurisemia, tekanan darah tinggi dan peningkatan glukosa darah yang merupakan salah satu ciri diabetes. Pemeriksaan kesehatan secara rutin berkala, pola hidup yang sehat dan kesadaran untuk tetap patuh dalam meminum obat merupakan upaya yang harus dijaga agar lansia tetap sehat. Pemeriksaan kesehatan periode tahun 
depan sebaiknya dilakukan secara seragam pada setiap pertemuannya. Hal ini bertujuan agar hasil pemeriksaan yang didapat mampu menunjukkan ada/tidaknya perubahan tekanan darah, kadar kolesterol, gula darah dan asam urat pada anggota yang sama. Selain itu, untuk mengetahui adanya hubungan antara pengetahuan/ penyuluhan yang diberikan dengan peningkatan kesadaran kesehatan pada anggota Perhimpunan Warakawuri St. Monika Samarinda, maka perlu dilakukan kuisioner sebelum menerima penyuluhan dan kuisioner setelah penyuluhan.

\section{UCAPAN TERIMA KASIH}

Terima kasih kami sampaikan kepada STIKES Dirgahayu Samarinda melalui Lembaga Penelitian dan Pengabdian Masyarakat (LPPM) serta Perhimpunan Warakawuri Santa Monika Samarinda sehingga penyusun dapat menyelesaikan kegiatan pengabdian masyarakat ini dengan baik.

\section{DAFTAR PUSTAKA}

El Khoudary et al. (2018). HDL (HighDensity Lipoprotein) Metrics and Atherosclerotic Risk in Women: Do Menopause Characteristics Matter? MESA. American Heart Association Journals Arterioscler Thromb Vasc Biol. 2018;38:2236-2244.DOI: 10.1161/ATVBAHA.118.311017. Diperoleh pada 12 November 2018 dari

https://www.ahajournals.org/doi/pdf/ $\underline{\text { 10.1161/ATVBAHA.118.311017 }}$

Kementerian Kesehatan RI. (2016). Situasi Lanjut Usia (Lansia) di Indonesia. Jakarta Selatan: Pusat Data dan Informasi Kementerian Kesehatan Republik Indonesia

Kementerian Kesehatan RI. (2017). Analisis Lansia di Indonesia. Jakarta Selatan: Pusat Data dan Informasi
Kementerian Kesehatan Republik Indonesia.

Novitaningtyas T. (2014). Hubungan Karakteristik (Umur, Jenis Kelamin, Tingkat Pendidikan) dan Aktivitas Fisik dengan Tekanan Darah Pada Lansia di Kelurahan MakamHaji Kecamatan Kartasura Kabupaten Sukoharjo. Diperoleh pada tanggal 2 Desember 2018 dari http://eprints.ums.ac.id/29084/9/02. Naskah Publikasi.pdf

Perhimpunan Warakawuri Katolik Santa Monika Indonesia. (2017). Panduan Loka Karya Perhimpunan Warakawuri Katolik Santa Monika Indonesia. Sangkal Putung : Perhimpunan Warakawuri Katolik Santa Monika Indonesia.

Sunaryo, dkk. (2016). Asuhan keperawatan Gerontik. Yogyakarta: Andi Offset.

Watson, R. (2003). Perawatan pada Lansia. Jakarta: Buku Kedokteran EGC.

WHO. 2010. Definition of an Older or Elderly Person. Geneva, Switzerland: WHO. Diperoleh pada 3 Agustus 2018 dari http://www.who.int/healthinfo/survey /ageingdefnolder/en/index.html

Woodard et al. (2011). Lipids, Menopause, and Early Atherosclerosis in SWAN Heart Women: Menopausal Transition and Lipids. National Institutes of Health Public Access. Menopause. 2011 April; $18(4)$ : 376-384. DOI:10.1097/gme.0b013e3181f6480e . Diperoleh pada 27 Oktober 2018 dari

https://www.ncbi.nlm.nih.gov/pmc/ar ticles/PMC3123389/pdf/nihms272901.pdf 